\title{
RESEARCH PROGRESS OF SOURCE AND MECHANISM OF AGRICULTURAL NON-POINT SOURCE POLLUTION IN CHINA
}

\author{
SHOU, C. G. - DU, H. S. * - LIU, X. P. \\ College of Tourism and Geographical Science, Jilin Normal University \\ NO.1301, Haifeng Street, Siping 136000, China \\ (phone: +86-185-4349-9109; fax: +86-434-329-2077) \\ *Corresponding author \\ e-mail: duhs@163.com; phone: +86-151-4466-1359; fax:+86-434-329-2077 \\ (Received $1^{\text {st }}$ Mar 2019; accepted 21 ${ }^{\text {st }}$ May 2019)
}

\begin{abstract}
Agricultural non-point source pollution of aquifer, lake, riverbank and other ecosystems is caused by chemical fertilizer, pesticide, animal manure and other organic or inorganic pollutants through surface runoff and farmland leaching in agricultural production. The non-point source pollution has the characteristics of wide distribution, concealment, randomness, hysteresis and complex formation mechanism, and thus it is difficult to study and control this type of pollution. Understanding the mechanism of agricultural non-point source pollution and comprehensively being aware of the pollution sources are of great theoretical and practical significance for future research. In this paper, the mechanism of agricultural non-point source pollution was analysed in terms of rainfall and runoff process, soil erosion process, pollutant migration and transformation, and so on. In addition, the sources and sinks of nitrogen, livestock and poultry pollutants, pesticides, plastic film and other pollution sources were discussed, and the results could be informative for the formulation of agricultural sustainable development policies.
\end{abstract}

Keywords: non-point source pollutants, agricultural runoff, livestock and poultry raising, pesticide pollution, contaminant transport, geographic information system

\section{Introduction}

With the continuous strengthening of human economic activities, water environmental pollution has become a global problem. According to the types of pollution, it is divided into point source and non - point source. Point source pollution has been effectively treated by controlling industrial wastewater and urban sewage, but the problem of non-point source pollution has not been effectively solved. Agricultural non-point source pollution is caused by the non-point-source pollutants including chemical fertilizers, pesticides, livestock and poultry manure, and farmland leachate, produced in agricultural production processes (Wang et al., 2007). In recent years, agricultural non-point source pollution has been worsened and drawn more attention. Agricultural non-point source pollution can lead to surface water eutrophication and groundwater pollution, threatening aquatic habitats. Hence, it has been regarded as one of the main pollution sources of surface water and groundwater (Ma et al., 2003). Compared to point source pollution, non-point source pollution has a wider space-time range, greater uncertainty and affected by many factors such as geographical conditions, climate conditions, soil structures and vegetation coverage, thus increasing the difficulty of research, decontamination and management (Pei et al., 2010; Babin et al., 2016). At present, many scholars have studied on the agricultural non-point source pollution, and governments have also been involved in the management and abatement of agricultural non-point source pollution. 
At present, the pollution composition is rapidly transformed in China (Chen et al., 2004). Especially, the excessive application of nitrogen and phosphorus fertilizers in China rural area has caused serious environmental problems. Because Livestock-poultry farming and domestic sewage was not centralized and treated, a large amount of manure was directly disposed of into the water body through surface runoff generated by rainstorm. Consequently, the problem of agricultural non-point source pollution in a watershed was aggravated. In this paper, pollutant sources and process and mechanism on non-point source pollution were reviewed and the information obtained could be beneficial for the formulation of agricultural sustainable development policies in China.

\section{Sources of pollutants}

\section{Sources and sinks of nitrogen}

In order to comprehensively understand the current situation of total nitrogen pollution in the water source area of the Middle Route Project of the South to North Water Diversion and effectively grasp the sources of pollution and formulate systematic countermeasures, Xin and $\mathrm{Xu}$ (2018) carried out the field monitoring and data collections of 7 reservoir sections, 16 reservoir tributaries and 62 typical reservoir bays in Danjiangkou Reservoir area. The environmental issues resulting from nitrogen have been extensively studied (Jacobsen et al., 2016; Walters et al., 2017), but most of the studies only focused on a specific problem, and rarely conducted comprehensive studies on the various links of nitrogen cycles in watersheds (Rowe et al., 2016). Therefore, the understanding of the nitrogen cycles in watersheds is usually one-sided and not qualified to provide scientific information for the decision-making of environmental management in the watersheds (Table 1).

Table 1. China's pesticide application and main grain production from 2010 to $2016\left(10^{4} t\right)$

\begin{tabular}{c|c|c|c|c|c|c|c}
\hline Item & $\mathbf{2 0 1 0}$ & $\mathbf{2 0 1 1}$ & $\mathbf{2 0 1 2}$ & $\mathbf{2 0 1 3}$ & $\mathbf{2 0 1 4}$ & $\mathbf{2 0 1 5}$ & $\mathbf{2 0 1 6}$ \\
\hline Pesticide & 175 & 179 & 181 & 180 & 181 & 179 & 175 \\
Staple food & 54648 & 57121 & 58958 & 60194 & 60703 & 62144 & 61625 \\
\hline
\end{tabular}

Sha et al. (2018) carried out model analysis on the characteristics of the load flux and source composition of the total nitrogen pollutants in the water body, employed The regional nutrient management model (ReNuMa) to model the total nitrogen source apportionments of Lianjiang River and estimate the future pollution fluxes and contribution proportion under changed climate conditions, which were further compared to current status to estimate the response of watershed non-point source pollution to climate change. To date, the research on the deposition of atmospheric nitrogen has not been sufficiently done in China. Thus, the basic data are insufficient, and the research methods and technologies are still developing. At present, merely scattered data of rainwater nitrogen contents in China have been reported, and the quantitative studies on the dry and wet deposition intensities, space-time distribution and the sources of atmospheric nitrogen at watershed scales have not been documented (Singh and Pandey, 2018). Collected surface water samples from Guanzhong area, Shanxi, in the Weihe River Basin so as to prevent and control the nitrate nitrogen $\left(\mathrm{NO}_{3}{ }^{-}-\mathrm{N}\right)$ pollution of the surface water in the watershed. For this purpose, Zhang et al. (2018) have done the 
hydrochemical assessment and nitrogen isotopic measurement to determine the pollution levels of nitrate by identifying its main pollution sources on the water surface. Limited by experimental conditions, the applications of stable nitrogen isotopes in the identification of atmospheric nitrogen deposition and nitrogen sources of surface water were rarely attempted in China (Xiao and Liu, 2002).

\section{Livestock and poultry breeding pollutants}

After the reform and opening in China, the livestock and poultry breeding industry in China has been developed rapidly (Qian et al., 2018), but some of the farms possessed poor equipment and bad management, resulting in pollution problems because of livestock and poultry waste (Huang et al., 2006). China began to recognize the harm of livestock and poultry waste to environment in 1990s (Wang et al., 2017a). However, the research on this kind of pollution was still developing in China. Ji et al. (2017) took the total nitrogen emission from livestock and poultry breeding in the Zhexi Reservoir Basin as the research object, calculated the water environment capacity and the total nitrogen pollutant emission load of livestock and poultry breeding on the small watershed scale, and determined the response relationship between the environment capacity of the river basin and the total nitrogen emission of the livestock and poultry according to the pollutant discharge contribution rates of different industries. Wang et al. (2017b) conducted hotspot analyses for total and respective livestock numbers in China for the years 1992, 2002, and 2012. Based on these analyses, the main livestock pollutants of the hot spot provinces were estimated using the discharge coefficient method. In order to characterize the spatial distribution of non-point source pollution in the Yanghe Reservoir watershed, based on land use, agricultural management, and other data, Chen et al. (2018) calculated the load of four pollutants (TN, TP, $\mathrm{NH}_{3}-\mathrm{N}$ and COD). Pollutant sources included domestic wastewater, solid waste, livestock and poultry breeding, chemical fertilizer loss, soil erosion and urban runoff. The spatial distribution of sources was analyzed using ArcGIS. In practice, the rapid development of livestock and poultry breeding in China has significantly affected the regional environmental quality (Xu et al., 2018), and the surface water and groundwater in certain regions have been largely polluted. Due to the lack of understanding of the various loss routes of livestock and poultry breeding waste and the quantitative migration rules of nutritional elements, the environmental pollution issues ascribed to livestock and poultry breeding have not been quantitatively studied, which affects the development of livestock and poultry pollution management regulations.

\section{Pesticides pollution}

Excessive unreasonable application of pesticides causes pollution (Vryzas, 2018; Yang et al., 2018). According to the literatures, more than $84 \%$ of peasants applied pesticides in excess of the standards (Li and Yin, 2001). As a result, highly toxic and highly persistent pesticides would be discharged into the environment, polluting crops, soil, atmosphere and water (Yang et al., 2009). The excessive application leads to the majority of pesticides were discharged into the soil and atmosphere (Lai, 2017). Hu et al. (2016) collected rice and soil samples from 11 counties and cities around Poyang Lake according to the pollution status of organic chlorine pesticides (OCPS) pollution in rice and soil in the area around Poyang Lake, and used Gas chromatograph - electron capture detector (GC-ECD) technology to determine organo chlorine residue. The OCPs from the rice samples were evaluated with the health risk assessment model. With the 
aim of ecological restoration for surface water that suffered from pesticides and domestic waste water pollution in a agricultural village, Jin et al. (2017) established a Vallisneria natans and Hydrilla verticillata demonstration area in August 2015, and evaluated the effect of submerged vegetation restoration on the control of seven pesticides, the recovery of macrozoobenthos and the reduction of conventional water quality indicators. At present, the relative research in China mainly focused on the highly persistent organ chlorine pesticides (Yuan et al., 2003; Kang et al., 2003). Because of their persistence, the pollution effect of organochlorine pesticides residues on the soil in China will last for a long time. In addition, at present, the research on widespread and highly toxic organophosphorus pesticides (Wu et al., 2018; Chahkandi et al., 2019) focused on the development of detection methodology and analysis of the residues over vegetables, fruits and crops (Wan et al., 2004; Yang et al., 2004).

\section{White pollution}

Since the 1980s, agricultural film mulching technology has been widely applied. This technology has brought economic benefits but caused serious environmental problems (Yang et al., 2009). The agricultural film has remarkable effects in resisting natural disasters, expanding planting area of crops and increasing yields. Meanwhile, the plastic residues harm the environment and soil (Yan et al., 2006). A large amount of residual agricultural film was dispersed in soil and could not be degraded, which not only reduced the permeability, water content, and drought resistance of farmlands, but also seriously affected the growth of plant roots and water-fertilizer transport, resulting in the reduction of crops yields ( $\mathrm{Hu}$ and Zhang, 2003). To date, the number and distribution of agricultural film residues in local regions and the harm to soil and crops growth have been extensively studied, but long-term, systematic and large-scale followup studies and observation experiments are still insufficient.

\section{Mechanism study}

\section{Surface runoff}

The runoff formed by rainfall is a carrier for non-point source pollutants migration and transformation (Ma, 2019). Thus, the characteristics of runoff generation and confluence as a response to rainstorm events were usually investigated from the points of view of hydrology and hydrodynamics. At the beginning, a typical SCS-CN model (Soil Conservation Service-Curve Number, USDA-SCS, 1972) was usually adopted in the research on non-point source pollution. Afterwards, Lutz revised the SCS method by taking the soil moisture conditions (such as basic flow factor) in the early stage into account, which renders the Lutz method more accurate in the simulation of hydrological parameters. During the same period, a number of watershed hydrological models were also developed (Villamizar and Brown, 2016), such as the Stanford Watershed Model (SWM) (Crawford, 1996). In the early 1960s, the excess storage, excess infiltration and integrated runoff generation theories were proposed in China ( $\mathrm{Hu}$ and $\mathrm{Lu}, 2019)$. These theories have been gradually applied in the studies on the non-point source pollution. In addition, in view of the small number of non-point source pollution monitoring data in China, Li (2000) proposed a simple and practical average-concentration algorithm for estimating the non-point source pollution load in watersheds based on the formation process of pollution. Liang et al. (2005) used a small-scale artificial rainfall simulator to 
launch natural heavy rain experiments in four typical land-use types around the Guanting Reservoir. On the basis of the experiments, the migration process of nitrogen and phosphorus along with rainstorm runoff and runoff sediments was studied, and the loss rates of total nitrogen and total phosphorus in different land-use types were also estimated. In order to investigate effects of under different vegetation coverage $(0 \%$, $15 \%, 30 \%, 45 \%, 60 \%, 75 \%, 90 \%)$, slope lengths $(3 \mathrm{~m}, 4 \mathrm{~m}, 5 \mathrm{~m})$ and fertilizer treatments (control $(\mathrm{CK})$ and compound N-P-K fertilizer $(\mathrm{CF})$ ) on runoff producing processes and nitrogen loss, Wu et al. (2019) conducted an artificial simulated rainfall experiment.

\section{Soil erosion}

Soil erosion issue is common in the world, and it affects the production and livings of people (Yuan et al., 2019). Soil erosion is one of the primary forms of agricultural non-point source pollution (Zhang et al., 2019). In the late 1960s, the Universal Soil Loss Equation (USLE) was prevalent in the simulation and estimation of long-term average soil loss in the erosion processes of slope lands (Wischmeier and Smith, 1978). Huang et al. (2003) predicted the non-point source pollution load discharged into the Yahekou reservoir using the USLE equation, which taking six factors of rainfall, soil erodibility, slope length, slope, and crop and management measures into account. This model was continuously revised and extended until a Revised Universal Soil Loss Equation (RUSLE) model (Daniel et al., 1994) was developed. Wang (2006) adopted the RUSLE equation and SCS hydrological model to estimate the nitrogen and phosphorus pollution loads in the Chaohu Lake Watershed. Zhou et al. (2015) systematically evaluated and analyzed the risks of agricultural non-point source pollution in the Ashi River Watershed based on a modified universal soil loss equation (MUSLE) model. In the early 1980s, a WEPP (Water Erosion Prediction Project) model was proposed to study the mechanism of soil erosion. On the basis of the meteorological data and soil erosion moduli of field runoff plots in Huajiang demonstration area in 2006 and 2010, Long et al. (2014) estimated the annual average soil erosion moduli at different rocky desertification levels, and evaluated the applicability of the WEEP model in Karst rocky desertification area. Likewise, on the basis of the meteorological data and monitoring data of field runoff plots in an experimental station in Binxian County, Heilongjiang Province in 2008, Liu et al. (2010) estimated the secondary rainfall runoff and soil loss in the black soil area of Northeast China using the WEPP model, and evaluated the applicability of WEPP model by comparing with the measured data. Wang et al. (2019) selected seven sub-basins of the Chaohu Basin as the target area, established a sediment delivery distribution model to quantitatively estimate the particulate phosphorus loading modules (PPLM) of the Chaohu Basin in 2015 and determined the differences in the loss of particulate phosphorus and their causes under different land use patterns.

\section{Migration and transformation of pollutants}

The migration of non-point source pollutants refers to the process of non-point source pollutants diffusing from the soil circle to other circles ( $\mathrm{Lu}$ and Xie, 2018), especially the hydrosphere, under the action of external forces (rainfall, irrigation, etc.). Some of the agricultural non-point source pollutants were discharged into ditch wetland systems along with field drainage. After the interception and reduction by the ditch wetland systems, the residual pollutants were eventually discharged into rivers, lakes 
and other water bodies (Wei et al., 2016), causing pollution to the surface water environment (Chen, 2000). A series of studies have been launched on the relationships between nitrogen and phosphorus loss due to farmland rainfall runoff and farmland tillage patterns, crops growth seasons, rainfall characteristics, land utilization, topographic conditions and vegetation cover (Hong et al., 2007). Liu et al. (1988) investigated the non-point source pollution in the Yuqiao Reservoir Watershed of Tianjin City and the results showed that vegetation was a key factor restricting the spatial variability of non-point source pollution (Figure 1).

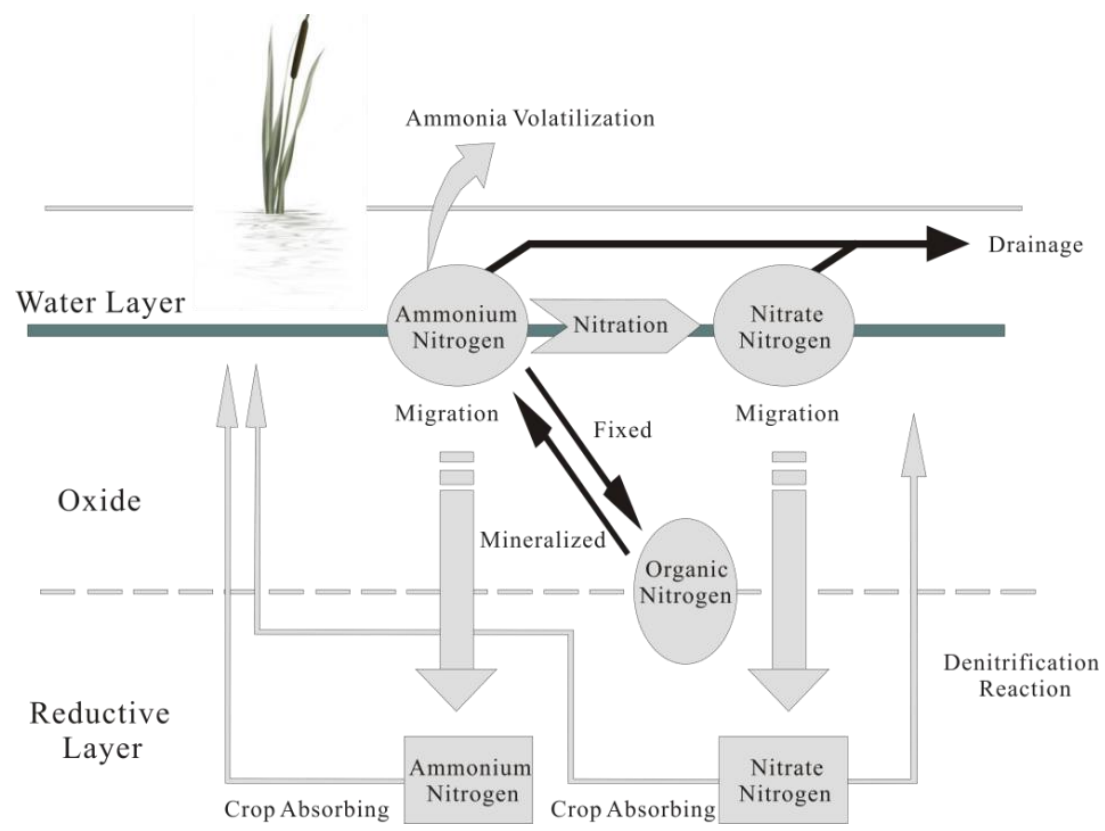

Figure 1. Conversion of ammonium and nitrate nitrogen

Shen et al. (2014) conducted a simulated experiment to determine the interception effectiveness of runoff, sediment, nitrogen, and phosphorus by artificial grass-like Vegetative filter strips (VFS) with different widths. The results indicate that grass VFS are very effective in reducing runoff, sediment, nitrogen, and phosphorus and controlling agricultural non-point source pollution. Kang et al. (2018) investigated and analysed the characteristics of application and surface runoff loss of nitrogen and phosphorus fertilizers in nine cities of Fujian Province during the years of 1985 to 2016. Additionally, they analysed the risk grades of farmlands pollution due to nitrogen and phosphorus fertilizers considering nitrogen and phosphorus fertilizers runoff loss, rainfall and river network density. At the same time, the spatial distribution characteristics of nitrogen and phosphorus contaminated regions were presented through the geographic information system (GIS) analysis. Li et al. (2017) divided paddy field water into surface and subsurface waters. The leaching of surface water and the dissolved solute $\mathrm{NH}_{4}{ }^{+}, \mathrm{NO}_{3}{ }^{-}$and $\mathrm{PO}_{4}{ }^{3-}$ within it were calculated using water-balance method. Water in the soil was simulated numerically from transient flow equation, from which Li et al. (2017) calculated the discharge rate to drainage ditch. Water flow in the drainage network was simulated using the wave equation and the biochemical reaction of the solutes was described by first-order kinetics. 


\section{Conclusions and prospects}

The mechanism of non-point source pollution was discussed in terms of rainfall and runoff processes, soil erosion process and pollutants migration and transformation processes in this paper. In addition, the non-point-source pollutant sources were analysed in terms of nitrogen sources and sinks, livestock and poultry breeding pollution, chemical fertilizer and pesticide pollution, and white pollution.

The future research should embark on the following: First, the basic monitoring should be enhanced because the agricultural non-point source pollution research should not be separated from field tests and monitoring data. Therefore, the field test, monitoring and management are required to be reinforced, and the correlations between the database of different regions and different watersheds should be increased. Secondly, the pollution research models suitable for China's situations should be established; the agricultural non-point source pollution research models suitable for China's different regions should be established; the agricultural non-point source pollution research in regions without data or with data difficult to derive should be done. Thirdly, the crossresearch between related subjects and related fields should be conducted; the agricultural non-point source pollution research should be closely related with geography, ecology, economics, management and other disciplines.

Agricultural non-point source pollution control and management will be a long-term and gradual process, and we can make efforts in the following aspects. First, the simple and cheap alternative technology is the key to the control of agricultural non-point source pollution. Finding alternative economic, simple and feasible technical system to control agricultural non-point source pollution, establishing causality between economic behavior and pollution hazard is the basis of formulating control policy. Second, the promotion and demonstration project operation management mechanism. These include the construction of agricultural non-point source pollution control demonstration area, the formulation of agricultural non-point source pollution control project long-term management mechanism, the establishment of long-term supervision institutions and strengthening the construction of farmers' professional organizations. Third, there should be different management policies for different pollution sources. For example, the use of chemical fertilizers and pesticides can be controlled by levying taxes, subsidizing agricultural environmental policies and insuring against risks. Fourth, we should promote modern agricultural technologies, raise the level of agricultural production, implement multi-dimensional innovation, and comprehensively promote the prevention and control of agricultural non-point source pollution.

The mechanisms of agricultural non-point source pollution have been greatly developed. The relationships between the pollution and sustainable development of agriculture as well as the negative influences of the pollution on ecological environment and human health have been well agreed. The relative results have effectively promoted people's understanding of the serious environmental consequences of agricultural nonpoint source pollution.

Acknowledgements. The study was supported by the National Key Research and Development Program of China (2018YFD0300204). 


\section{REFERENCES}

[1] Babin, N., Mullendore, N., Prokopy, L. (2016): Using social criteria to select watersheds for non-point source agricultural pollution abatement projects. - Land Use Policy 55: 327-333.

[2] Chahkandi, M., Amiri, A., Arami, S. R. S. (2019): Extraction and preconcentration of organophosphorus pesticides from water samples and fruit juices utilizing hydroxyapatite/ $/ \mathrm{Fe}_{3} \mathrm{O}_{4}$ nanocomposite. - Microchemical Journal 144: 261-269.

[3] Chen, J. N., Li, G. H., Wang, H. T. (2004): Research on area source pollution controlling technology for the Dianchi Lake. - China Water Resources 9: 47-50.

[4] Chen, P., Fu, C. F., Ji, X. G. (2018): Spatial distribution characteristics of non-point source pollution load in yanghe reservoir basin. - Journal of Hydroecology 39(06): 58-64.

[5] Cheng, Q. G. (2000): Influence of non-point source pollutants on environment and trend analysis. - Environmental Protection and Re-Cycling Economy 5: 4-6.

[6] Crawford, N. H. (1966): Digital Simulation in Hydrology: Stanford Watershed Model IV. - Evapotranspiration 39.

[7] Daniel, T. C., Sharpley, A. N., Edwards, D. R., Wedepohl, R., Lemunyon, J. L. (1994): Minimizing surface water eutrophication from agriculture by phosphorus management. Journal of Soil and Water Conservation 49(2): 30-38.

[8] Hong, H. S., Zhang, Y. Z., Cao, Z. W. (2007): Study on non-point source pollution in the Wuchun catchment of Jiulong River. - Beijing: Science Press 2007.

[9] Hu, Y., Zhang, H. J. (2003): Research progress of calculation and control of non- point source pollution. - Journal of Anhui Agricultural Sciences 31(5): 788-790.

[10] Hu, C. H., Chen, L. L., Li, Y. H. (2016): Pollution of paddy rice and soil organochlorine pesticides and health risk assessment in poyang lake area. - Environmental Chemistry 35(02): 355-363.

[11] Hu, J. H., Lu, J. (2019): Landscape patterns regulate non-point source nutrient pollution in an agricultural watershed. - Science of the Total Environment 669.

[12] Huang, J. H., Li, Q., Tian, K. (2003): Prediction of non-point pollution load for Yahekou Reservoir. - Water Resources Protection 19(2): 28-30.

[13] Huang, J. J., Lin, C. W., Chen, Y. B., Zhang, Q. Y. (2006): Actualities and counter measures of non-point pollution of agriculture in China. - Anhui Agricultural Science Bulletin (12): 47-48.

[14] Jacobsen, B. H., Hansen, A. L. (2016): Economic gains from targeted measures related to non-point pollution in agriculture based on detailed nitrate reduction maps. - Science of the Total Environment 556: 264-75.

[15] Ji, Z. B., Wang, W. J., Liu, X. F., Xu, C., Wang, Y., Bai, Y., Qiu, W. T., Luo, L. (2017): Design of discharge permit system of livestock and poultry breeding: a case study in Zhexi Reservoir Basin. - Journal of Environmental Engineering Technology 7(05): 621628.

[16] Jin, C. C., Yang, Y., Liu, S. L. (2017): Ecological restoration of pesticides pollution in rural waste water. - Ecology and Environment 26(01): 142-148.

[17] Kang, Y. H., Liu, P. B., Wang, Z. J., Lv, Y. B., Li, Q. J. (2003): Persistent organochlorinated pesticides in water from Guanting Reservoir and Yongdinghe River, Beijing. - Journal of Lake Sciences 15(2): 125-132.

[18] Kang, Z. M., Zhang, R. X., Ye, Y. Z. (2018): Pollution risk assessment of nitrogen and phosphorus loss in surface runoff from farmland fertilizer in Fujian Province based on GIS. - Chinese Journal of Eco-Agriculture.

[19] Lai, W. Y. (2017): Pesticide Use and Health Outcomes: Evidence from Agricultural Water Pollution in China. - Journal of Environmental Economics and Management S0095069617303169.

[20] Li, H. E. (2000): Mean concentration method for estimation non-point source pollution load and its application. - Acta Scientiae Circumstantiae 20(4): 397-400. 
[21] Li, B. G., Yin, C. Q. (2001): Water environment problems and control measures of 3lakes in China. - Water Issues Forum (3): 36-39.

[22] Li, Y. Q., Zhang, C., Zhang, W. X. (2017): Simulating the transport and transformation of non-point contaminants in paddy field within an irrigated district 36(11): 29-35.

[23] Liang, T., Wang, H. P., Zhang, X. M. (2005): Simulation study of non-point source pollution under different land use in Guanting Reservoir watershed. - Acta Scientiae Circumstantiae 25(4): 483-490.

[24] Liu, F., Wang, H. D., Liu, P. T. (1988): The quantitative identification of non-point source pollution and its application in Yuqiao reservoir watershed. - Acta Geographica Sinica (4): 329-340.

[25] Liu, Y. L., Zheng, F. L., Wang, B., Wang, Y. X., Xie, Y. J., Fan, H. (2010): Assessment of WEPP model applicability in black soil zone of Northeast China-- A case study of slope gradient and soil and water conservation measures. - Bulletin of Soil and Water Conservation 30(1): 139-145.

[26] Long, M. Z., Wu, K. H., Xiong, K. N. (2014): Assessment of the applicability of the WEPP model (Hillslope Version) for soil erosion in karst rock desertification area, Guizhou Province. - Carsologica Sinica 33(2): 201-207.

[27] Lu, H., Xie, H. L. (2018): Impact of changes in labor resources and transfers of land use rights on agricultural non-point source pollution in Jiangsu Province, China. - Journal of Environmental Management 207.

[28] Ma, W. C., Chen, L. M., Li, J. Z. (2003): Progress in the research of non-point source pollution models of aquatic environment. - Advances in Earth Science 18(3): 358-366.

[29] Ma, H. (2019): Runoff simulation of agricultural non-point source pollution model in liaohe river basin. - Heilongjiang Science and Technology of Water Conservancy 2: 2226.

[30] Pei, L., Wang, L. M., Yu, G. Q. (2010): Status of study on agricultural non-point source pollution and new progress of its application. - Water Resources and Hydropower Engineering 41(12): 58-61.

[31] Qian, Y., Song, K., Hu, T., Ying, T. (2018): Environmental status of livestock and poultry sectors in China under current transformation stage. - Science of The Total Environment 622-623: 702-709.

[32] Rowe, E. C., Jones, L., Dise, N. B., Evans, C. D., Mills, G., Hall, J., Stevens, C. J., Mitchell, R. J., Field, C., Caporn, S. J. M., Helliwell, R. C., Britton, A. J., Sutton, M. A., Payne, R. J., Vieno, M., Dore, A. J., Emmett, B. A. (2016): Metrics for evaluating the ecological benefits of decreased nitrogen deposition. - Biological Conservation S0006320716308552.

[33] Sha, J., Lu, R., Xu, Y. X. (2018): Estimation of watershed non-point source pollution response toward climate change: a coupled modeling approach. - Environmental Science and Technology 41(06): 181-187.

[34] Shen, X. B., Chen, C. S., Zhang, Z., Sun, X. T., Xiao, B. (2014): Interception of runoff, sediment, nitrogen and phosphorus by vegetative filter strips with different width in a simulated experiment. - Journal of Agro-environmental Science 33(04): 721-729.

[35] Singh, R., Pandey, J. (2018): Non-point source-driven carbon and nutrient loading to Ganga River (India). - Chemistry and Ecology 1-17.

[36] Villamizar, M. L., Brown, C. D. (2016): Modelling triazines in the valley of the River Cauca, Colombia, using the annualized agricultural non-point source pollution model. Agricultural Water Management 177.

[37] Vryzas, Z. (2018): Pesticide fate in soil-sediment-water environment in relation to contamination preventing actions. - Current Opinion in Environmental Science and Health 5-9.

[38] Walters, C. G., Shumway, C. R., Huggins, D. R. (2017): Impacts of terrain attributes on economics and the environment: costs of reducing potential nitrogen pollution in wheat production. - Agricultural Economics 48(2): 143-152. 
[39] Wan, Y. Q., Chen, Y. Q., Zhan, C. R. (2004): Determination of multi-organophosphorous pesticide residuals in sesame seeds by capillary gas chromatography. - Chinese Journal of Analysis Laboratory 23(7): 10-12.

[40] Wang, X. H. (2006): Study on non-point source pollution of Nitrogen and Phosphorus drainage evaluating and it's controlling on in ChaoHu watershed. - Hefei: Hefei University of Technology. (in Chinese).

[41] Wang, Z. M., Zhang, B., Song, K. S., Liu, D. W., Yan, B. X., Hu, L. J., Yang, H. J., Xu, J. P., Yang, F., Duan, H. T. (2007): Domestic and overseas advances of nonpoint source pollution studies. - Chinese Agricultural Science Bulletin 23(9): 68-68.

[42] Wang, H., Xu, J., Liu, X., Sheng, L., Zhang, D., Li, L., Wang, A. (2017a): Study on the pollution status and control measures for the livestock and poultry breeding industry in northeastern China. - Environmental Science and Pollution Research 4435-4445.

[43] Wang, J. X., Xu, F., Liu, R. M. (2017b): Analysis of spatial hot spots of total livestock and poultry production in China and calculation of major pollutants. - Journal of AgroEnvironment Science 36(07): 1316-1322.

[44] Wang, Z. F., Lin, C., Xu, J. D., Jin, P. H., Xiong, J. F., Min, M., Ma, R. H. (2019): Spatial differences in non-point source particle phosphorus loads and critical influence factors in the Chaohu Basin. - Journal of agro-environmental sciences 38(03): 659-670.

[45] Wei, O. Y., Wei, J., Li, X. M., Giubilato, E., Critto, A. (2016): Long-term agricultural non-point source pollution loading dynamics and correlation with outlet sediment geochemistry. - Journal of Hydrology 540: 379-385.

[46] Wischmeier, W. H., Smith, D. D. (1978): Predicting rainfall erosion losses - a guide to conservation planning. - Agric Handbook 537.

[47] Wu, P., Zhang, Y., Chen, Z., Wang, Y. L., Zhu, F. F., Cao, B., Wu, Y., Li, N. (2018): The organophosphorus pesticides in soil was degradated by Rhodobacter sphaeroides after wastewater treatment. - Biochemical Engineering Journal 141.

[48] Wu, Y. H., Zhang, L. P., Qian, J. (2019): Research on multi-factor effect of nitrogen loss in slope runoff. - Journal of Natural Disasters 28(01): 44-53.

[49] Xiao, H. Y., Liu, C. Q. (2002): Sources of nitrogen and sulfur in wet deposition at Guiyang, southwest China. - Atmospheric Environment 36(33): 5121-5130.

[50] Xin, X. K., Xu, J. F. (2008): Countermeasures for total nitrogen pollution control in water source area of middle route project of south to north water diversion. - Yangtze river 49(15): 7-12.

[51] Xu, P. C., Zhou, X., Xu, D. F., Xiang, Y. B., Ling, W. T., Chen, M. D. (2018): Contamination and Risk Assessment of Estrogens in Livestock Manure: A Case Study in Jiangsu Province, China. - International Journal of Environmental Research and Public Health 15(1): 125-127.

[52] Yan, C. R., Mei, X. R., He, W., Zheng, S. (2006): Present situation of residue pollution of mulching plastic film and controlling measures. - Transactions of the Chinese Society of Agricultural Engineering 22(11): 269-272.

[53] Yang, J. L., Liu, L. P., Li, L. (2004): Simultaneous determination of organophosphorus pesticide in vegetables with chromatography. - Journal of Environment and Health 21(4): 251-252.

[54] Yang, S. J., Zhang, A. P., Yang, S. Q., Yang, Z. L. (2009): Status analysis of agricultural non-point source pollution and advances in domestic and overseas. - Chinese Journal of Agrometeorology 30(s1): 82-85.

[55] Yang, F. Y., He, Q., Chen, Y. Q. (2018): Evaluation of pesticide contamination and edible risk in enteromorpha entire body in subei shoal of southern yellow sea. - Journal of agricultural and environmental sciences 37(06): 1108-1116.

[56] Yuan, X., Wang, Y., Chen, J., Sun, C., Xu, N. (2003): Organochlorine residues of sediments in Taihu Lake and its risk evaluation. - Environmental Science 24(1): 121-125. 
[57] Yuan, X. F., Han, J. C., Shao, Y. J., Li, Y. H., Wang, Y. S. (2019): Geodetection analysis of the driving forces and mechanisms of erosion in the hilly-gully region of northern Shaanxi Province. - Journal of Geographical Sciences 29(05): 779-790.

[58] Zhang, Y., Zhang, X., Bi, Z. L. (2018): Nitrate nitrogen pollution and source trace in the surface water of Guanzhong area, Shaanxi, in the Weihe River Basin. - Journal of Safety and Environment 18(06): 2395-2400.

[59] Zhang, T., Yang, Y. H., Ni, J. P., Xie, D. (2019): Adoption behavior of cleaner production techniques to control agricultural non-point source pollution: A case study in the Three Gorges Reservoir Area. - Journal of Cleaner Production 223: 897-906.

[60] Zhou, H., Lei, G. P., Feng, X. J. (2015): MUSLE -based risk evaluation of agricultural non -point source pollution in the Ash River watershed. - Research of Agricultural Modernization 36(3): 469-476. 